Pakistan Journal of Education

Vol.36, No.2, 2019, 63-76

\title{
Evaluation of Daily Duty Plan of Secondary School Heads in Perspective of TASPA Model
}

\author{
Tasleem Ullah* \\ Iftikhar Ahmed Baig $^{* *}$
}

\begin{abstract}
This research provided the theoretical orientation for examining school heads daily duty schedule/plan. The research provided that could help to evaluate and validate the proposed School Heads Daily Duty Plan. Objectives of study were to develop and validate TASPA Model Daily Duty Plan for Secondary School Heads. It was a descriptive research which aimed to assess the impact of Time, Activity, Strategy, Progress, Assessment Oriented TASPA Model designed as School Heads Daily Duty Plan. Population of the study consisted of all public sector secondary School Heads in Punjab. The accessible involved population was 270 Secondary School Heads in nine districts of three divisions in central Punjab. Randomly three districts from each division and three tehsils from each district were selected for the study. Questionnaire was used as an instrument of the study. Data were categorized according to five point Likert scale.t-test was applied. Conclusion was the finalized validated TASPA Model based Daily Duty Plan (DDP) for the Secondary School Heads as an end-product of study. It was a validated tool for the secondary school educational leadership for supervising the institutions in an efficient, productive and useful manner on daily basis.
\end{abstract}

Keywords: TASP a model-time-activity-strategy-progress-assessment, evaluation, validation.

\footnotetext{
* PhD (Education) Scholar, University of Lahore. Email address: tujundran1@gmail.com

** Head, Department of Education The University of Lahore . Email address: Iftikhar.ahmad@ed.uol.edu.pk
} 


\section{Introduction}

Planning is the process of designing and making objective use of available resources for the realization of educational aims and objectives of an organization. Planning is deciding in progress what to do, how to do it, when to do it and who to do it (Fremer, 2010). Educational planning may be defined as a set of decisions for future action pertaining to education. Educational planning is linked up with economic development which further depends upon overall manpower planning (Reddy, 2004). Schneider (2008) points out that a good plan covers an appropriate time frame. It is informed by the past but focused on the future. It commits to a single target growth. It articulates what one won't do. It maintains consistent attitude. Vallikkad (2011) says that a plan consists of study, skills, strategy, goals, and word as list of main ideas, note ideas in complete sentences. School Heads have to plan on daily basis for the better functioning of their institutions. Harris (2006) says that School Heads change the instructional superiority of schools. But, unexpectedly little is well-known about what principals / school heads do on a day-to day basis and how this varies across schools. James (2000) points out that school heads work days can provide an instructive window. Demopoulos (2014) notes that head of schools who start the morning with intent to visit classrooms often locate themselves waylaid by students, teachers, staff, and parents with urgent troubles to be solved. Already, annual plans have been introduced in local school education system. Comprehensive Daily Duty Plans (DDPs) especially for the School Heads are not in practice in the local scenario. Heads of institutions can play important role in the improvement of high - quality schools if they run the schools according to standardized and validated supervisory plans. While in this study, Daily Duty Plan for School Heads has been introduced for enhancing the efficiency and output of School Heads on daily basis.

According to Jundran (2014), it was proposed by the Directorate of Staff Development (DSD) Lahore that Cluster Training \& Support Centre Heads (CTSC Heads) may submit oral and verbal papers presentations through multimedia upon the specific topic at their respective Tehsil and District headquarter. Subsequently, District topqualified papers presentations were recommended for onward delivery at regional DSD headquarter.So far the authenticity of the proposed TASPA Model Daily Duty Plan (DDP) (2014) is concerned, all the Activities proposed in this DDP have been identified in the light of 
circulars/orders and directions issued by the School Education Department, Government of the Punjab (Pakistan), in different annals of time. Primary components of this plan consist of Time schedule, schedule of Activities, supportive mechanism Strategies for activities fulfillment, Progress indicators for the fulfillment of functions and Assessment of the progress level of activities accomplishment. The TASPA Model Daily Duty Plan (DDP) has been designed to keep each day of the school meaningful and functional up to optimal level.

\section{Objectives of Study}

The Objectives of study were: (i) To examine the TASPA Model Daily Duty Plan (2014) as daily supervisory model for Secondary School Heads; (ii) To validate the need of supervisory Activities identified in TASPA Model Daily Duty Plan for Secondary School Heads on daily basis; (iii) To try out the respective Strategies identified in TASPA Model Daily Duty Plan for the implementation of supervisory Activities for Secondary School Heads on daily basis; (iv) To ascertain the validity of TASPA Model Daily Duty Plan in the light of Secondary School Heads feedback; (v) To develop and validate TASPA Model Daily Duty Plan for Secondary School Heads.

\section{Review of the Related Literature}

The review segment discusses the role of Secondary School Heads. It elaborates their leadership, administration, supervision and management along with the concept of school development and improvement of educational models and validation have also been discussed in this section.

\section{Secondary School Heads: Significant Position in the Institution}

A Head is supported to build the civilization of excellence that penetrates to the minimum basics, and systems of an organization (Bush, 2010).All Heads of the institutions from Primary to Higher Secondary stage have complete power to allot his staff organizational duty during or after office hours as well as other program or periods, games, collection duty, plantation, assessment, documentation preparation (School Education Department, 2009). The Head of an organization would be accountable for its suitable supervision and management (Government of the Punjab, 2004).The Heads of institutions are accountable for their proper management and supervision of institutions and boarding house / hotel attached to it (Punjab Education Code 2005). All Heads of institutions may employ impermanent teachers for teaching Science and 
English subjects with lowest accepted requirement and salary set by the Government for this justification from Faroogh-e-Taleemfund (School Education Department, 2009). Secondary School Head would be responsible for the implementation of the policies instruction issued by the School Education Department / Government / Higher Authorities from time to time (Government of the Punjab, 2007).

\section{Educational Planning and Administration}

Nehru (2013) said that Planning included the possibility of better performance on all jobs. In the field of educational administration, planning ensured more effective decision making and more satisfying outcome. According to Jarral (2007) goals should be congruent with those of the course mentor and that they clearly define that students will do. These goals should be communicated to students. Tripathi (2005) says that the educational planning has been defined in various ways. It can be called a deliberate and conscious choice of educational priorities by a central agency.

Sharma (2008) says that administration in education is readily silent when it is remembered that political premise must at some point classify clearly the purposes of education and then go on to establish the type of administration which seems best suitable to the achievement of the type of people the State wished to construct. Kumar (2003) stated that many efforts have been made at various levels and at different times to make tangible improvements in education. Tangible improvement in the administration and supervision of education also depends upon the priorities of a political government set for education of the state. Among the other compared educational administration and leadership models, the major merits of TASPA DDP Model reflect as under:

It is the latest model. It incorporates the leading practices, important factors, salient features, prominent levels and the basic dimensions of the previous Models as well. It is comprehensive in adoption and implementation style. It focuses upon all key dimensions of a school. It is daily based Model and practically operational Model. Its each and every 'Activity' is authentic and state oriented. This Model is task- result oriented. Its major merit is its building upon team-work. It enables all members of the organization to act and perform. It describes delegation of responsibilities at each stage of school work. It is a needbased Model. Its start from "Activity" stage and its end upto "Assessment" stage in every period, on daily basis makes this Model, very smart and efficient one. By planning, this TASPA DDP Model is academic as well as master planned Model. Initially, it has been prepared for academic excellence enhancement in the learners' knowledge. 
Finally, it envisages the growth and progress of whole institution. It is actionable, feasible, adaptable and supervisable in nature. Basically, it is authentic, democratic and technocratic in letter and spirit. It is innovative and pioneer in daily model planning. Time is the most valuable asset of an organization which can never be regained. This TASPA Model regulates the school administrator and its whole staff towards its accountable task for each and every minute of the day.

\section{Research Methodology}

By purpose, it was an applied research. The research provided the theoretical and practical model for school heads for running school on daily bases and examining School Heads daily duty schedule /plan performance. Here, this basic research provided data that could help, support, guide, evaluate and validate the proposed School Heads Daily Duty Plan.

\section{Population}

Population of the study consisted of all public sector secondary School Heads working in Punjab province. The number of male secondary school heads in the Punjab province was 3355. It was the target population of the study. The accessible involved population for this study was the number of 270 Secondary School Heads working in nine districts of three divisions situated in central Punjab.

\section{Sample of the Study}

The random sample technique was involved into this study. Randomly three districts from each division and three tehsils from each district were chosen for this study. Thus, 270 Secondary School Heads were chosen through random sampling from nine districts and twenty seven tehsils of the respective nine districts.

\section{Instruments of the Study}

Questionnaire for the development and validation of TASPA Model DDP for Secondary School Heads was used as an instrument of the study. Questionnaire for Secondary School Heads was developed consisting of (35) items at five pointlikert scale (agree, strongly agree, undecided, disagree, strongly disagree) for the respondents for seeking their response about the identified Activities and relevant Strategies given into the TASPA Model. 


\section{Pilot Testing of Research Instrument}

Before conveying the Questionnaire to the participants, it was tried out in a pilot study. A focus group of thoughtful and critical individuals similar to the research participants was chosen. The copies of the Questionnaire were distributed among that focus group to get information about the deficiencies and improvements with reference to the theme and diction of Question statements. One of the participants of this group expressed his view that anonymity and confidentiality of the information provided by School Heads must be promised.

\section{Reliability of the Research Instrument}

Prior to administering the instrument at macro level, a pilot study on small scale was conducted on 20 Secondary School Heads who were in the population but not in the sample to test the reliability of the research instrument. Cronbach's alpha for the self-developed questionnaire was calculated to check the reliability which came up to 0.850 .

\section{Mode of Data Collection}

The researcher sought formal permission from the District Education Authority (concerned district) for seeking relevant information from the Secondary School Heads. After the grant of permission, the researcher conveyed the Questionnaire for the Development and Validation of TASPA Model to the Secondary School Heads through Pak post / courier service for data collection. After this, the researcher telephonically contacted those Heads for furnishing the information through filled in Questionnaires. The researcher had nominated honorary Focal person in each tehsil as data collector. Those Focal persons i.e., Data Collectors were taken from school education department upon the basis of professional links. Self-stamped (Return-Postage-Affixed) envelops were handed over to those data- collectors for sending back the filled in Questionnaires collected from the respondents.

\section{Procedure of Data Analysis}

The suitability of Activities for inclusion into the TASPA Model was analyzed in the light of Punjab Education Code, Dustor-ul-Amal and the latest School Education Department's official circulars. for Data was categorized according to five point Likert scale. There were five options. T-Test was applied for validation of Activities and respective Strategies proposed in TASPA Model (DDP) through SPSS. Their frequency was 
counted down. Data analysis made through both qualitatively and quantitatively ultimately accomplished validation of TASPA Model Daily Duty Plan for Secondary School Heads.

Table 1

Secondary School Heads Responses Obtained through Questionnaire Regarding Activities No 01-35

\begin{tabular}{|c|c|c|c|c|c|}
\hline \multicolumn{2}{|c|}{ Activities No } & 1 & MEAN & 2 & SD \\
\hline \multicolumn{2}{|c|}{ Activity No 1} & 3 & 2.03 & 4 & 1.011 \\
\hline \multicolumn{2}{|c|}{ Activity No 2} & 5 & 2.21 & 6 & 1.021 \\
\hline \multicolumn{2}{|c|}{ Activity No 3} & 7 & 2.46 & 8 & 1.109 \\
\hline 9 & ACTIVITYNO4 & 10 & 1.94 & 11 & 1.028 \\
\hline 12 & ACTIVITY NO 5 & 13 & 2.27 & 14 & 1.191 \\
\hline 15 & ACTIVITY NO 6 & 16 & 4.01 & 17 & 2.12 \\
\hline 18 & ACTIVITY NO 7 & 19 & 2.07 & 20 & 1.109 \\
\hline 21 & ACTIVITY NO 8 & 22 & 4.12 & 23 & 2.25 \\
\hline 24 & ACTIVITY NO 9 & 25 & 1.83 & 26 & 1.101 \\
\hline 27 & ACTIVITY NO 10 & 28 & 2.19 & 29 & 1.134 \\
\hline 30 & ACTIVITY NO 11 & 31 & 2.65 & 32 & 1.153 \\
\hline 33 & ACTIVITY NO 12 & 34 & 4.10 & 35 & 2.20 \\
\hline 36 & ACTIVITY NO 13 & 37 & 2.69 & 38 & 1.261 \\
\hline 39 & ACTIVITY NO 14 & 40 & 1.94 & 41 & 1.028 \\
\hline 42 & ACTIVITY NO 15 & 43 & 1.93 & 44 & 1.101 \\
\hline 45 & ACTIVITY NO 16 & 46 & 2.15 & 47 & 1.036 \\
\hline 48 & ACTIVITY NO 17 & 49 & 4.75 & 50 & 2.04 \\
\hline 51 & ACTIVITY NO 18 & 52 & 4.65 & 53 & 2.01 \\
\hline 54 & ACTIVITY NO 19 & 55 & 2.31 & 56 & 1.094 \\
\hline 57 & ACTIVITY NO 20 & 58 & 2.04 & 59 & 1.194 \\
\hline 60 & ACTIVITY NO 21 & 61 & 2.37 & 62 & 1.133 \\
\hline 63 & ACTIVITY NO 22 & 64 & 1.80 & 65 & 1.013 \\
\hline 66 & ACTIVITY NO 23 & 67 & 2.25 & 68 & 1.145 \\
\hline 69 & ACTIVITY NO 24 & 70 & 4.09 & 71 & 2.19 \\
\hline 72 & ACTIVITY NO 25 & 73 & 1.69 & 74 & 1.101 \\
\hline 75 & ACTIVITY NO 26 & 76 & 4.75 & 77 & 2.04 \\
\hline 78 & ACTIVITY NO 27 & 79 & 2.25 & 80 & 1.154 \\
\hline 81 & ACTIVITY NO 28 & 82 & 4.08 & 83 & 2.03 \\
\hline 84 & ACTIVITY NO 29 & 85 & 2.31 & 86 & 1.094 \\
\hline 87 & ACTIVITY NO 30 & 88 & 2.35 & 89 & 1.309 \\
\hline 90 & ACTIVITY NO 31 & 91 & 4.13 & 92 & 2.17 \\
\hline 93 & ACTIVITY NO 32 & 94 & 2.21 & 95 & 1.100 \\
\hline 96 & ACTIVITY NO 33 & 97 & 1.68 & 98 & 1.026 \\
\hline 99 & ACTIVITY NO 34 & 100 & 1.80 & 101 & 1.013 \\
\hline 102 & ACTIVITY NO 35 & 103 & 1.79 & 104 & 1.012 \\
\hline $\begin{array}{l}\text { ACT } \\
01-3\end{array}$ & TY NO & & & & $47.721 \mathrm{~N}=270$ \\
\hline
\end{tabular}


Result in Table 1 shows Activities -wise option acquired through Secondary School Heads. Total number of respondents is 270. There are 6242 responses in favor of agree and 3208 responses in favor of disagree. So, total number of responses is 9450 acquired through 270 respondents. The above table shows that majority of Head Teachers $(66 \%)$ were agreed while $(34 \%)$ Head Teachers were disagreed regarding Activities No 1 to 35.There are thirty-five Activities in TASPA Model (DDP) Plan for Secondary School Heads. According to the responses of respondents nine Activities out of thirty-five Activities have been deleted from this TASPA Model. Sixty - six percent responses of agreed nature shows that twenty six Activities are valid and thirty-four percent responses of disagreed show that nine Activities are not valid in TASPA Model (DDP) for Secondary School Heads.

Table 2

Secondary School Heads Responses Obtained through Questionnaire Regarding Strategies No 01-35

\begin{tabular}{lllll}
\hline Strategies & 105 & MEAN & 106 & SD \\
& & & & \\
\hline $\begin{array}{l}\text { TASPA Strategies } \\
\text { No 1-35 }\end{array}$ & 107 & 92.89 & 108 & 47.721 \\
\end{tabular}

Result in Table 2 shows Strategies-wise option acquired through Secondary School Heads. Total numbers of respondents are 270. There are 5670 responses in favor of agree and 3780 responses in favor of disagree. So, total numbers of responses are 9450 acquired through 270 respondents. The above table shows that majority of Head Teachers $(60 \%)$ were agreed while $(40 \%)$ Head Teachers were disagreed regarding Strategies No 1 to 35. There are thirty five Strategies in TASPA Model (DDP) Plan for Secondary School Heads. According to the responses of respondents nine Strategies out of thirty five Strategies have been deleted from this TASPA Model. Sixty six percent responses of agreed shows that twenty six Strategies are valid and Thirty-four percent responses of disagreed show that nine Strategies are not valid in TASPA Model (DDP) for Secondary School Heads. 


\section{Findings of the Study}

Activities No 1-35: Sixty-six percent of Secondary School Heads population was agreed while Thirty-four percent of Secondary School Heads population was disagreed about the placement and need of these Activities at this time in TASPA Model (DDP). Thus, the majority of Head Teachers were agreed to these Activities of TASPA Model (DDP). (Table 1)

Strategies No 1-35: Sixty-percent of Secondary School Heads population was agreed while Forty percent of Secondary School Heads population was disagreed about the placement and need of these Strategies at this time in TASPA Model (DDP). Thus, the majority of Head Teachers were agreed to these Strategies of TASPA Model (DDP). (Table2)

\section{Discussion}

According to response of Respondents (Secondary School Heads) following Nine out of thirty five Activities and Strategies have been deleted from this TASPA Model. It reasons are as under:

Activity No. 06 was 'Watching sanitary condition of whole school.' Eighty Respondents reported, "Schedule this activity before start of school." One hundred and ten Respondents reported, "Due to work load no need of this Activity" It can be discussed here that majority of Respondents disagree this Activity so, this Activity has been deleted from this TASPA Model.

Activity No. 08 was "Proper parking \& gate security measures in the light of school security plan." Fifty eight Respondents reported, "Before school opening by a local person." Ten Respondents desired that proper parking and gate security measures should be ensured through local person before school opening'. One Hundred and Thirty Five Respondents reported that " Due to systematic plan, routine work is in therefore no need of this Activity" It can be discussed here that majority of Respondents dislike this Activity So, this Activity has been deleted from this TASPA Model.

Activity No. 12 was 'Telephonic contact with DTEs for ensuring their availability in their respective school.' All the Respondents are not interested to continue this Activity because the Government of Punjab has stopped this programme. It can be discussed here that Respondents dislike this Activity So, this Activity has been deleted from this TASPA Model. 
Activity No. 17 was 'Compliance of current directions of the Government for different schemes.' None of the Respondents like this activity. It can be discussed here that Respondents dislike this Activity So, this Activity has been deleted from this TASPA Model.

Activity No.18 was 'Taking a glass of simple water/ a cup of simple tea/ green tea as body regulator/ refresher, etc.' Sixty one Respondents reported," Difference from man to man, " Sixty two Respondents reported, "It depends on weather conditions and personal performance." Two Respondents proposed that they were agreed for this regulator / refresher: However type depends on personal choice and weather condition. It can be discussed here that Respondents dislike this Activity. So, this Activity has been deleted from this TASPA Model.

Activity No.24 was 'Provision of healthy, safe \& supportive recreative atmosphere to the students during recess.' None of Respondents interested for this Activity. It can be discussed here that Respondents dislike this Activity So this Activity has been deleted from this TASPA Model.

Activity No. 26 was 'Horticulture/ plantation work progress report collection.' Seventy nine Respondents reported, "Not possible on daily basis." Sixty Respondents reported, "This activity should be in early period." One hundred and ten Respondents proposed "Due to work load not possible." It can be discussed here that Respondents dislike this Activity so; this Activity has been deleted from this TASPA Model.

Activity No. 28 was "Keeping Liaison with DTEs daily visit in their respective schools." All the Respondents are not interested to continue this Activity because the Govt. of Punjab stop this programme. It can be discussed here that Respondents dislike this Activity So, this Activity has been deleted from this TASPA Model.

Activity No.31 was 'Surprise supervision and Disciplinary/ Motivational Round of some classes.' One hundred and sixty Respondents reported, "No need" Seventy proposed that he was not agreed for this activity because it was not needed. It can be discussed here that Respondents dislike this Activity So, this Activity has been deleted from this TASPA Model.

There are thirty five Activities and Strategies in this TASPA Model. Activities No 6,8,12,17,18,24,26,28,31 and Strategies No 
$6,8,12,17,18,24,26,28,31$ have been deleted from TASPA Model (DDP) according to response of Respondents (Secondary School Heads).

\section{Conclusion}

Conclusions reached through review of the findings of Respondents (Secondary School Heads) were as under:

The majority of Secondary School Heads (Respondents), i.e., 66\% found valid the TASPA Model Daily Duty Plan (DDP) Activities for themselves in their secondary schools. Similarly, the majority of Secondary School Heads (Respondents), i.e., 60\% found valid the TASPA Model Daily Duty Plan (DDP) Strategies for the conduct of prescribed Activities for themselves in their secondary schools. Strategies pertinent to their Activities also verified the need, adoption and usefulness of this plan for the secondary school education sector. The Concluding finalized and validated TASPA Model Daily Duty Plan (DDP) emerged as an end-product of the study with required revisions made in the light of 270 Secondary School Heads (Respondents) feedback.

Out of 35 Activities proposed in DDP, the time schedule of 05 Activities underwent change in the final product. The content of 09 (DDP) Activities underwent modifications in the final product. Out of 35 Activities proposed in 12 Activities has not change in TASPA Model Daily Duty Plan (DDP) in the final product. Out of 35 Activities proposed in TASPA Model (DDP) 09 Activities have been deleted in TASPA Model Daily Duty Plan (DDP) in the final product. Out of 35 Strategies proposed in TASPA Model (DDP) 09 Strategies have been deleted in TASPA Model Daily Duty Plan (DDP) 2014. Three Strategies out of 35 were also modified into (DDP) for the conduct of their relevant prescribed (DDP) Activities in the final product. The finalized validated TASPA Model (Time-Activity-Strategy-Progress-Assessment) (2018) based on twenty six Activities and Strategies Daily Duty Plan (DDP) for the Secondary School Heads of Punjab province was the end-product of this study. It was a validated tool for the secondary school education leadership for running the institutions in an efficient, productive and the useful manner on daily basis. Its implementation would be helpful in enhancing the output of school education department. 


\section{Recommendations}

School Education Department may provide the soft and hard copies of this validated TASPA Model (DDP) to all Secondary School Heads for its perused and subsequent implement. Directorate of Staff Development (DSD) Lahore may include this TASPA Model (DDP) into its training manuals developed for SS/HSS Heads. Furthermore, the TASPA Model (DDP) may be included as a topic of training designed for the school education administrators, managers. An Urdu version of TASPA Model may also be made available for the Secondary School Heads for its better understanding.

Accessories of TASPA Model (DDP), i.e., Schedule of teachers time table; Schedule of class wise time table; Schedule of practical subjects time table; Sports periods time table ; Schedule of library periods ; Gardening period time table, may also be made available to the Heads, Separate plan for Weekly, Fortnightly and Monthly schedule of discussion for (DDP) Activities. (a) School sanitation inspection; (b) Bazm-e-Adab programme; (c) School council meeting, etc), may also be provided to SS/ igher Secondary School Heads along with (DDP). 


\section{References}

Bush, T. (1989). Managing education: Theory and practice. Milton Keynes: Open University Press.

Demopoulos , K. (2014). Job realities of primary school principals in Greece: Similarities and variations in a highly centralized system. International Journal of Leadership in Education, 55-65

Fremer, (2010). Principles of management: Types of plan. Retrieved February 20, 2006, from www Cliff stone, Com / more - subjects.

Government of the Punjab. (2004). Dastoor-ul-Amal [The code of conduct]. Lahore: Department of School Education.

Harris, (2006). What principals look for when hiring teachers and implications for teachers quality policies. London: Delmar Publishers.

Jarral, R. (2007). Theory and practice of teaching. Lahore: Majeed Book Depot Publication.

Jundran, S.U. (2014). Development of school heads daily duty plan: CTSC Head's annual theoretical presentation top-ranked in district Mandi Baha-ul-Din. District Training \& Support Centre Mandi Bahaul-Din, Punjab.

Kumar, S. (2003). Educational planning and administration. New Delhi: National Institute of Educational Planning and Administration Publication.

Nehru, S. (2013). Educational administration, management planning. New Delhi: Publishing Corporation Ansari Road, Darya Gan.

Punjab Education Code. (2005). Rules and regulation for employees (English and Urdu) Lahore: Government of Punjab.

Reddy, R.S. (2004). Encyclopedic dictionary of education. (Part iii). New Delhi: Rajat Publication.

Schneider, J. (2008). Ten characteristics of a great strategic plan.

Retrieved from www the edu/ Journals/ foc/summary. 
School Education Department, (2007). Responsibilities of secondary school heads. Lahore: Government of Punjab Notification No. (PS / $\mathrm{SSE} / \mathrm{MISC} / 2009$ /81).

School Education Department, (2009). Empowerment of heads of educational institutions. Lahore: Government of Punjab Notification No.(PS/SSE/MISC/2009/81).

Sharma, P. (2008). Education administration. New Delhi: A.P.H.

Publishing Corporation.

Tripathi, R. (2005). Modern education planning and management. New Delhi: Radha Publication.

Valiked, S. (2011). Dictionary of teaching and learning. New Delhi: Kanishka Publisher Distributors India.

\section{Citation of this Article:}

Ullah, T., \& Baig, I. A. (2019). Evaluation of daily duty plan of secondary school heads in perspective of TASPA model. Pakistan Journal of Education, 36(2), 63-76. 